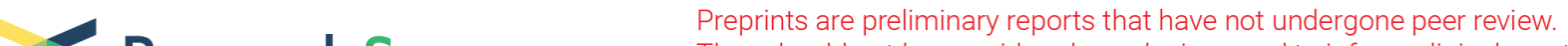 $\begin{array}{ll}\text { Research Square } & \text { They should not be considered conclusive, used to inform clinical practice, } \\ \text { or referenced by the media as validated information. }\end{array}$
}

\section{SOX7 blocks vasculogenic mimicry in oral squamous cell carcinoma}

\section{Kyoung-Ok Hong ( $\square$ hongko95@snu.ac.kr)}

Seoul National University School of Dentistry https://orcid.org/0000-0002-8401-552X

\section{Kyu-Young Oh}

Seoul National University School of Dentistry

\section{Hye-Jung Yoon}

Seoul National University School of Dentistry

\section{Neeti Swarup}

Seoul National University School of Dentistry

\section{Minjung Jung}

Seoul National University School of Dentistry

Ji-Ae Shin

Seoul National University School of Dentistry

\section{Jung-Hwan Kim}

Gyeongsang National University Graduate School of Medicine

\section{Jae-ll Lee}

Seoul National University School of Dentistry

\section{Sung-Dae Cho}

Seoul National University School of Dentistry

\section{Seong-Doo Hong}

Seoul National University School of Dentistry

\section{Primary research}

Keywords: Vasculogenic mimicry, SOX7, Oral squamous cell carcinoma, Prognosis, Lymph node metastasis

Posted Date: August 5th, 2020

DOl: https://doi.org/10.21203/rs.3.rs-53700/v1

License: (c) (i) This work is licensed under a Creative Commons Attribution 4.0 International License. Read Full License 


\section{Abstract}

Background : Vasculogenic mimicry (VM) is the formation of an alternative circulatory system by aggressive tumor cells. The characteristics of VM and its underlying mechanism in oral squamous cell carcinoma (OSCC) remain unclear. This study aims to determine the relationship between VM channels in OSCC tissues and clinical outcomes and to investigate the biological role of SOX7 in VM in OSCC cells. Methods : CD31/PAS double staining was performed to evaluate VM status in OSCC tissue. The relationships between VM and clinicopathological variables, and VM and SOX7 levels were analyzed. VM channel formation was assay performed to observe VM channels in the OSCC cell lines. To investigate the role of SOX7 in VM channel formation, SOX7 was transiently over-expressed in SCC-9 cells. VMmodulating genes were identified by Western blotting. Results : We confirmed the presence of VM channels in OSCC tissue and several cell lines and found a positive correlation between VM and lymph node metastasis and patient survival in OSCC $(P=0.003)$. We also found that the presence of VM channels in OSCC tissue was inversely associated with SOX7 expression $(P=0.020)$. We observed that overexpression of SOX7 impaired VM channel formation by reducing the expression of VE-cadherin, thereby inhibiting cell migration and invasion. Conclusion: These results suggest that SOX7 plays an important role in the regulation of VM channel formation and may inhibit OSCC metastasis.

\section{Background}

The formation of new blood vessels in solid tumors is essential for their growth and metastasis. Without the oxygen and nutrients provided by additional blood vessels, tumors undergo necrotic cell death due to ischemia and hypoxia [1, 2]. Conventional anti-angiogenic therapy, which targets vascular endothelial cells to inhibit tumor blood vessel formation, has proven unsatisfactory [2,3]. The failure of such therapy suggests that tumors have an alternative strategy beyond angiogenesis for attaining a blood supply adequate to sustain growth.

A new interpretation of previous findings was reported by Maniotis et al., who observed highly patterned vessel-like channels in human melanomas in which red blood cells were detected, independent of endothelium-dependent angiogenesis [4]. Formed by the process of vasculogenic mimicry (VM), these structures consist of periodic acid-Schiff (PAS) ${ }^{+}$and CD31-negative basement membranes lined by tumor cells rather than endothelial cells [5]. VM has been vividly described in numerous types of malignant tumors and is closely associated with a poor clinical outcome [6-8]. Experimental evidence has confirmed a relationship between VM and tumor metastasis in a variety of cancer cell lines and has shown that tumor cells can form VM channels in Matrigel culture [9-11]. The tumor cells lining VM networks express vascular endothelial cadherin (VE-cadherin) [12], erythropoietin-producing hepatocellular receptor A2 (EphA2) [13], and matrix metalloproteinases [14], the expression of which correlates with tumor metastasis and invasion [15]. Although many studies have contributed new insights into VM and its underlying molecular pathways $[3,16]$, the features of VM and its underlying mechanism in oral squamous cell carcinoma (OSCC) are still unclear. 
We recently reported that the expression of SOX7, a member of the sex-determining region Y-box (SOX) family, is associated with advanced TMN stage, lymph node metastasis, and poor overall survival in patients with OSCC [17]. Additionally, several studies have reported a tumor-inhibitory function of SOX7 associated with cancer regulatory pathways $[18,19]$. The effect of SOX7 on VM channel formation and the regulation of VM-related genes has not been studied in any cancer.

The present study investigates whether VM channels are present in human OSCC tissues and cell lines. The relationship between VM channels and clinical outcomes in OSCC tissues is examined, and the biological effect of SOX7 on VM channel formation in OSCC cells is explored.

\section{Methods}

\section{Patients and tissue specimens}

Specimens were retrieved from 46 patients with OSCC who were surgically treated at the Department of Oral and Maxillofacial Surgery at Seoul National University Dental Hospital between 1999 and 2005. Clinical data including age, sex, recurrence, and survival were collected from patient medical records. Tumors were graded based on the World Health Organization (WHO) Classification of Tumors [20] and staged according to the TNM system recommended by the American Joint Committee on Cancer [21]. The clinicopathological features of the OSCC patients are summarized in Table 1. This study was approved by the Institutional Review Board (IRB) of Seoul National University Dental Hospital (IRB number: ERI16008).

\section{CD31/ Periodic acid-Schiff (PAS) double staining}

Formalin-fixed, paraffin-embedded specimens were sectioned to a thickness of $4 \mu \mathrm{m}$. Tissue sections were deparaffinized in xylene and rehydrated in graded alcohol solutions. Endogenous peroxidase was inactivated by incubation in $3 \% \mathrm{H}_{2} \mathrm{O}_{2}$ solution for 5 min. Heat-induced epitope retrieval was performed in citrate buffer $\left(\mathrm{pH}\right.$ 6.0) for 10 min using a microwave oven. The sections were incubated overnight at $4^{\circ} \mathrm{C}$ with mouse monoclonal anti-CD31 (clone JC/70A; 1:100; Thermo Fisher Scientific, Rockford, IL, USA). The immunohistochemical reaction was performed using REAL EnVision/HRP (Dako, Glostrup, Denmark) and visualized by diaminobenzidine. Sections were incubated for $5 \mathrm{~min}$ in $0.5 \%$ periodic acid solution followed by $15 \mathrm{~min}$ in Schiff reagent. Slides were washed for 5 min in lukewarm water, counterstained with Mayer hematoxylin, dehydrated, and mounted. Endothelial cells were used as an internal positive control for CD31, and the primary antibody was omitted as the negative control.

\section{Identification of vasculogenic mimicry}

CD31/PAS double staining was evaluated blindly by two oral pathologists (KYO and SDH). Based on recent reviews of $\mathrm{VM}[22,23], \mathrm{VM}^{+}$was defined as the presence of $\mathrm{CD}^{2} 1^{-} / \mathrm{PAS}^{+}$vessel-like structures surrounded by tumor cells on the non-luminal side. Although red blood cells may be observed in the lumen, the absence of endothelial cells was confirmed by the absence of CD31 expression on the luminal 
side. Microscopic fields with prominent inflammatory infiltrates, necrosis, and hemorrhage were not included for VM evaluation. According to these criteria, all 46 OSCC cases were classified as $\mathrm{VM}^{+}$or $\mathrm{VM}^{-}$.

\section{SOX7 immunohistochemistry}

Formalin-fixed, paraffin-embedded specimens were immunohistochemically stained using rabbit polyclonal anti-SOX7 (1:50; Santa Cruz Biotechnology, Santa Cruz, CA, USA) as previously described [17]. Immunohistochemical staining was assessed semi-quantitatively by two oral pathologists (KYO and SDH). Tumor cells showing nuclear staining were considered positive. The percentage of positive cells was scored as follows: $0,0 \% ; 1,1-10 \% ; 2,11-50 \%$; and $3,51-100 \%$. Staining intensity was scored as follows: 0 , negative; 1 , weak (light brown); 2 , moderate (brown); and 3, strong (dark brown). A final score (0-9) was established by multiplying the percentage score by the intensity score. For statistical analysis, final scores $\geq 2$ were defined as $\mathrm{SOX7}^{+}$, and scores $<2$ as SOX7${ }^{-}$.

\section{Cell lines, Constructs, and Transfection}

HN22, YD-10B, and OSC-20 cells were kindly provided by Dankook University (Cheonan, Korea), Yonsei University (Seoul, Korea), and Hokkaido University (Hokkaido, Japan), respectively. SCC-9 cells were obtained from American Tissue Culture Collection (Manassas, VA, USA). OSCC cell lines were cultured in DMEM/F-12 medium (Welgene, Daegu, Korea) containing 10\% fetal bovine serum (FBS) and $100 \mathrm{U} / \mathrm{mL}$ penicillin/streptomycin in a humidified atmosphere containing $5 \% \mathrm{CO}_{2}$ at $37^{\circ} \mathrm{C}$. Cells expressing pCMV6Entry or pCMV6-SOX7 (RC210036, Origene, Rockville, USA) were transiently transfected with JET-PEI reagent (Polyplus-transfection, NY, USA).

\section{Western Blot Analysis}

Cell lysates were prepared by homogenization with RIPA buffer (EMD Millipore, Billerica, CA, USA) according to the protocol supplied. Protein concentrations was measured using the DC Protein Assay Kit (Bio-Rad Laboratories, Hercules, CA, USA). After normalization, equal amounts of protein were separated by sodium dodecyl sulfate-polyacrylamide gel electrophoresis and transferred to immunoblot polyvinylidene difluoride membranes (Pall Corporation, Port Washington, NY, USA). The membrane was blocked with $5 \%$ skim milk at room temperature for $2 \mathrm{~h}$, incubated with specific primary antibodies, and probed with the corresponding horseradish peroxidase-conjugated secondary antibodies (GTX213110 for anti-Rabbit and GTX213111 for anti-mouse). Antibodies against SOX7 (SC-20093), VE-cadherin (SC9989), and a-tubulin (SC-5286) were obtained from Santa Cruz Biotechnology. Rabbit anti-human monoclonal antibody against EphA2 (\#6697) was obtained from Cell Signaling Technology, Inc (Danvers, MA, USA). The immunoreactive proteins were detected by SuperSignal West Pico Chemiluminescent Substrate (SC-2048; Santa Cruz Biotechnology), and immunoreactive bands were visualized using ImageQuant LAS 500 (GE Healthcare Life Sciences, Pittsburgh, PA, USA). Densitometric analysis of western blots was performed using ImageJ software (Version 1.51k, NIH, Bethesda, MD, USA).

\section{Three-dimensional culturing for VM channel formation assay}


A 24 well plate was coated with $150 \mu \mathrm{L}$ of growth factor reduced Matrigel (BD Bioscience, Bedford, MA, USA), and the cell suspension was seeded onto the solid Matrigel at a concentration of $1.5 \times 10^{5}$ cells with serum-free medium. After incubation for $24 \mathrm{~h}$, cells were stained with PAS (Thermo Fisher Scientific) to label the basement membrane of tubular structures. Five random fields of view for channels and intersections were photographed at 100x magnification using an inverted microscope (Nikon Ti, Nikon Instruments Inc., Melville, USA) and counted using Image J software. Network Intersection was defined as a junction between 3 neighbors [24].

\section{Cell migration and Invasion assays}

To assess cell migration and invasion, cells $\left(8 \times 10^{4}\right.$ cells/well) were suspended in $0.5 \mathrm{~mL}$ of serum-free DMEM/F12 medium. For cell migration assays, collagen type I (BD Bioscience) was diluted in cold PBS solution and dried on the lower surface of transwell membranes (8- $\mu \mathrm{m}$ pore size, Corning, Lowell, MA, USA). For invasion assays, the upper surface of the transwell membrane was pre-coated with a 1:15 dilution of growth factor reduced Matrigel (BD Bioscience). The bottom chamber was then filled with medium containing $10 \%$ FBS as a chemoattractant. The transwell chamber was incubated at $37^{\circ} \mathrm{C}$ with $5 \% \mathrm{CO}_{2}$ for $24 \mathrm{~h}$. Non-migrating and non-invading cells were removed from the top chamber with a cotton swab. Cells remaining on the lower surface were fixed with $100 \%$ methanol and stained with hematoxylin and eosin. The number of cells on the bottom chamber was counted under a light microscope (Leica DM5000B, Leica Microsystems, Wetzlar, Germany). For each assay, 10 different microscopic fields (100x magnification) were randomly selected.

\section{Statistical analysis}

Pearson chi-square test and Fisher's exact test were performed to evaluate the association between VM status and clinicopathological features or SOX7 expression. Cumulative survival curves were generated using the Kaplan-Meier method, and the difference between the curves was analyzed using the log-rank test. All in vitro data are expressed as the mean \pm standard deviation (SD). The statistical comparisons between groups were evaluated using Student's $t$-test for two groups. $\mathrm{P}<0.05$ was considered statistically significant. All statistical analyses were performed using IBM SPSS Statistics version 25 (IBM, Armonk, NY, USA).

\section{Results}

\section{VM was associated with poor prognosis in OSCC patients}

VM was identified in $23.9 \%(11 / 46)$ of the OSCC specimens studied. PAS ${ }^{+}$tubular structures were lined by endothelial-like tumor cells with $\mathrm{CD} 31^{-}$staining (Figures $1 \mathrm{~A}$ and $\mathrm{B}$ ). Vascular-like structures were observed in 3 OSCC cell lines (HN22, OSC20, and YD10B), and PAS ${ }^{+}$staining indicating VM channel formation was observed (Figure 1C). VM was significantly associated with lymph node metastasis $(P=$ 
0.003) (Table 2). The 5-year survival rate was $47.8 \%(22 / 46)$ in patients with OSCC, and the $\mathrm{VM}^{+}$group tended to have lower overall survival $(P=0.073$ ) (Figure 1D).

\section{VM correlated with absence of SOX7 expression in OSCC}

Of the 46 OSCC specimens, 14 (30.4\%) were classified as SOX7', and all were $\mathrm{VM}^{-}$(Figure 2). All VM ${ }^{+}$ exhibited no nuclear staining for SOX7, indicating a strong association between the positive VM status and the absence of SOX7 expression in OSCC $(P=0.020)$ (Table 3).

\section{SOX7 impaired VM channel formation in vitro}

To assess the influence of SOX7 expression on VM channel formation in vitro, SCC-9 cells were transiently transfected with a SOX7 overexpression vector (Figures 3A and 3B). SOX7 and control (transfected with vehicle vector) cells were then cultured on Matrigel for $24 \mathrm{~h}$. SCC-9 cells transfected with SOX7 had fewer channels than did control cells and did not form extensive channel networks (Figure 3C). These results were confirmed by PAS staining of VM networks (Figure 3C) and quantification of channel formation and the number of channel intersections indicated a decrease in VM channel formation in SOX7-overexpressing cells (Figure 3D). VE-cadherin and EphA2 have been identified as major proteins involved in VM channel formation [12]. While the expression of EphA2 did not change significantly, we found that only VE-cadherin expression was reduced in SOX7-overexpressing cells (Figures 3E and 3F).

\section{SOX7 inhibited the migration and invasion of SCC-9 cells}

VM channel formation is thought to be related to tumor cell migration and invasion [5]. To investigate the function of SOX7 expression in the migration and invasion ability of SCC-9 cells, we performed transwell migration and invasion assays in SCC-9 cells. As expected, SOX7 overexpression strongly inhibited the migration and invasion capacity of SCC-9 cells (Figure 4).

\section{Discussion}

Avascular tumors $\left(>1-2 \mathrm{~mm}^{3}\right)$ cannot be sufficiently supplied with oxygen and nutrients and cannot rely entirely on host endothelial cells for angiogenesis [25]. Therefore, tumors require a system independent of angiogenesis, such as VM. A three-stage phenomenon underlies VM: 1) highly malignant tumor cell plasticity, 2) remodeling of the extracellular matrix (ECM), and 3) connection of VM channels and host blood vessels to obtain a blood supply from the host tissue [26]. Since the first description of VM in uveal melanoma, a CD31 ${ }^{-} / \mathrm{PAS}^{+}$profile has been recognized as the hallmark of VM $[10,24,27]$. In this study, we observed small vessel-like structures with a lumen lined with tumor cells in OSCC tissue (Figures 1A and 1B). VM channels were also detected in several OSCC cell lines using Matrigel culture system (Figure 1C). In addition, the occurrence of VM was positively associated with lymph node metastasis (Table 2), and Kaplan-Meier survival analysis showed that $\mathrm{VM}^{+}$OSCC patients had a worse overall survival rate than did $\mathrm{VM}^{-}$patients (Figure 1D). Our present findings are consistent with a recent meta-analysis reporting that VM is associated with lymph node metastasis and overall survival in patients with squamous cell 
carcinoma of the head and neck [28]. These observations strongly suggest that VM may be used as an independent predictor of prognosis in OSCC.

We previously demonstrated that SOX7 expression was lower in OSCC tissue samples than in corresponding normal oral mucosal tissues and that the absence of SOX7 expression was significantly associated with advanced TNM stage, incidence of lymph node metastasis, and poor prognosis [17]. SOX7 expression was found to be frequently down-regulated in a variety of tumors; its forced expression inhibited cellular proliferation, migration, and invasion, suggesting that SOX7 functions as a tumor suppressor [29-31]. Because both VM and SOX7 are closely associated with OSCC prognosis, we hypothesized that SOX7 might play an essential role in VM channel formation in OSCC. In the present study, we observed VM channels in 34.4\% of OSCC in the absence of SOX7 expression; SOX7 expression correlated negatively with VM status (Figure 2 and Table 3). In vitro experiments also showed that overexpression of SOX7 severely disrupted the formation of VM channels in SCC- 9 cells in a Matrigel culture system (Figure 3C and 3D). These results further support the hypothesis that SOX7 regulates VM channel formation in OSCC. To the best of our knowledge, this is the first report elucidating the role of SOX7 in VM in OSCC.

Given that tumor cells can be transformed into endothelial-like cells (mesenchymal cells), many studies have proposed that the epithelial-mesenchymal transition (EMT) is vital for VM [32-35]. A recent study reports that the EMT-related transcription factors Twist1 and Snail were up-regulated in $\mathrm{VM}^{+}$ hepatocellular carcinoma samples and that their expression correlated with VM channel formation [33, 36]. In contrast, our results show that VM status was not associated with the expression of Snail or Twist in OSCC (data not shown), indicating that other factors are involved in VM in OSCC. VM-associated molecules and signaling pathways have been investigated in numerous types of highly aggressive malignant tumors and have served as a strategic roadmap for drug development [15]. VE-cadherin, a transmembrane protein in the cadherin family, is expressed exclusively by endothelial cells [37]. Expressed in highly aggressive melanoma cells, its down-regulation was observed to abolish VM, indicating its involvement in VM structure formation [38]. VE-cadherin also mediates the activities of EphA2, a member of the ephrin-receptor family of PTKs, which is crucial for angiogenesis [39]. Mitra et al., recently found that phosphorylation of EphA2 was significantly associated with the occurrence of VM in invasive breast carcinoma [40]. Co-localization of VE-cadherin with EphA2 is reported to induce the activation of MMPs, resulting in matrix remodeling and VM channel formation [12, 15, 41]. These findings suggest that VE-cadherin, EphA2, and MMPs are important VM-modulating genes. In this study, we observed that SOX7 overexpression significantly attenuated the protein expression of VE-cadherin in SCC9 cells but did not affect VM-modulating genes such as EphaA2 and MMP-2 and -9 (Figure 2E;

Supplementary Figure 1). These results suggest that the molecule responsible for the observed regulatory effects of SOX7 on VM channel formation in OSCC is VE-cadherin.

\section{Conclusion}


Our findings show that the occurrence of VM correlated positively with lymph node metastasis and may be a promising marker of patient prognosis in OSCC. We also provide evidence that the presence of VM channels in OSCC tissue is inversely associated with SOX7 expression and that SOX7 restrains in vitro VM channel formation by inhibiting VE-cadherin expression. To the best of our knowledge, this study is the first to demonstrate that SOX7 plays an important role in VM and consequently contributes to OSCC suppression. Therefore, further investigation of $\mathrm{SOX7}$ as a potential therapeutic strategy for inhibiting VM channel formation in OSCC is necessary in the future.

\section{Abbreviation}

SOX7: Sex-determining region Y-box (SOX) family; VM: Vasculogenic mimicry; OSCC: Oral squamous cell carcinoma; PAS: Periodic acid-Schiff; VE-cadherin: Vascular endothelial cadherin; EphA2: Erythropoietinproducing hepatocellular receptor A2; PTK: Protein tyrosine kinases; EMT: Epithelial-mesenchymal transition; MMPs: Matrix metalloproteinases.

\section{Declarations}

\section{Ethics approval and consent to participate}

This study was approved by the SNUDH (Seoul National University Dental Hospital) Institutional Review Bord.

\section{Consent for publication}

Not applicable.

\section{Availability of data and materials}

The datasets used and/or analyzed during the current study are available from the corresponding author upon reasonable request.

\section{Competing interests}

The authors declare that they have no competing interests.

\section{Funding}

Not applicable.

\section{Authors' contribution}

Study concepts: SDH, KOH; Study design: KYO, HJY, SDC; Data acquisition: KOH, KYO, NS; Quality control of data and algorithms: MJ, JHK, JAS; Data analysis and interpretation: $\mathrm{KOH}, \mathrm{KYO}, \mathrm{SDH}$; Statistical 
analysis: NS, JIL, MJ, JHK; Manuscript preparation: HJY, JAS, KYO; Manuscript editing: SDC, KOH; Manuscript review: SDC, SDH. All authors read and approved the final manuscript.

\section{Acknowledgments}

We would like to thank Enago (www.enago.co.kr) for English language editing. This work was supported by the Basic Science Research Program through the National Research Foundation of Korea (NRF) funded by the Ministry of Science, ICT, and Future Planning [2018R1D1A1B07043080, 2019R1A2C1085896, and 2020R1F1A1050880].

\section{References}

1. Carmeliet P, Jain RK: Molecular mechanisms and clinical applications of angiogenesis. Nature.2011;473(7347):298-307.

2. van Beijnum JR, Nowak-Sliwinska P, Huijbers EJ, Thijssen VL, Griffioen AW: The great escape; the hallmarks of resistance to antiangiogenic therapy. Pharmacol Rev.2015;67(2):441-61.

3. Viallard C, Larrivee B: Tumor angiogenesis and vascular normalization: alternative therapeutic targets. Angiogenesis.2017;20(4):409-26.

4. Maniotis AJ, Folberg R, Hess A, Seftor EA, Gardner LM, Pe'er $\mathrm{J}$ et al: Vascular channel formation by human melanoma cells in vivo and in vitro: vasculogenic mimicry. Am J Pathol.1999;155(3):739-52.

5. Qiao L, Liang N, Zhang J, Xie J, Liu F, Xu D et al: Advanced research on vasculogenic mimicry in cancer. J Cell Mol Med.2015;19(2):315-26.

6. Luo Q, Wang J, Zhao W, Peng Z, Liu X, Li B et al: Vasculogenic mimicry in carcinogenesis and clinical applications. J Hematol Oncol.2020;13(1):19.

7. Yang JP, Liao YD, Mai DM, Xie P, Qiang YY, Zheng LS et al: Tumor vasculogenic mimicry predicts poor prognosis in cancer patients: a meta-analysis. Angiogenesis.2016;19(2):191-200.

8. Liu R, Yang K, Meng C, Zhang Z, Xu Y: Vasculogenic mimicry is a marker of poor prognosis in prostate cancer. Cancer Biol Ther.2012;13(7):527-33.

9. Xia Y, Cai XY, Fan JQ, Zhang LL, Ren JH, Chen J et al: Rho Kinase Inhibitor Fasudil Suppresses the Vasculogenic Mimicry of B16 Mouse Melanoma Cells Both In Vitro and In Vivo. Mol Cancer Ther.2015;14(7):1582-90.

10. Xia Y, Cai XY, Fan JQ, Zhang LL, Ren JH, Li ZY et al: The role of sema4D in vasculogenic mimicry formation in non-small cell lung cancer and the underlying mechanisms. Int J Cancer.2018.

11. Zhang J, Qiao L, Liang N, Xie J, Luo H, Deng G et al: Vasculogenic mimicry and tumor metastasis. J BUON.2016;21(3):533-41.

12. Delgado-Bellido D, Serrano-Saenz S, Fernandez-Cortes M, Oliver FJ: Vasculogenic mimicry signaling revisited: focus on non-vascular VE-cadherin. Mol Cancer.2017;16(1):65.

13. Hess AR, Seftor EA, Gruman LM, Kinch MS, Seftor RE, Hendrix MJ: VE-cadherin regulates EphA2 in aggressive melanoma cells through a novel signaling pathway: implications for vasculogenic 
mimicry. Cancer Biol Ther.2006;5(2):228-33.

14. Hess AR, Seftor EA, Seftor RE, Hendrix MJ: Phosphoinositide 3-kinase regulates membrane Type 1matrix metalloproteinase (MMP) and MMP-2 activity during melanoma cell vasculogenic mimicry. Cancer Res.2003;63(16):4757-62.

15. Kirschmann DA, Seftor EA, Hardy KM, Seftor RE, Hendrix MJ: Molecular pathways: vasculogenic mimicry in tumor cells: diagnostic and therapeutic implications. Clin Cancer Res.2012;18(10):272632.

16. Abdalla AME, Xiao L, Ullah MW, Yu M, Ouyang C, Yang G: Current Challenges of Cancer Antiangiogenic Therapy and the Promise of Nanotherapeutics. Theranostics.2018;8(2):533-48.

17. Oh KY, Hong KO, Huh YS, Lee JI, Hong SD: Decreased expression of SOX7 induces cell proliferation and invasion and correlates with poor prognosis in oral squamous cell carcinoma. J Oral Pathol Med.2017;46(9):752-8.

18. Wang L, Fan Y, Zhang L, Li L, Kuang G, Luo C et al: Classic SRY-box protein SOX7 functions as a tumor suppressor regulating WNT signaling and is methylated in renal cell carcinoma. FASEB J.2019;33(1):254-63.

19. Zhang Y, Stovall DB, Wan M, Zhang Q, Chou JW, Li D et al: SOX7 Target Genes and Their Contribution to Its Tumor Suppressive Function. Int J Mol Sci.2018;19(5).

20. et alEl-Naggar AK, Chan JKC, Grandis JR, Takata T, Slootweg PJ. Tumours of the nasal cavity, paranasal sinuses and skull base. WHO Classification of Head and Neck Tumours. In.: Lyon: IARC Press; 2017.

21. Amin MB, Edge SB: AJCC cancer staging manual: springer; 2017.

22. Hujanen R, Almahmoudi R, Karinen S, Nwaru BI, Salo T, Salem AJC: Vasculogenic Mimicry: A Promising Prognosticator in Head and Neck Squamous Cell Carcinoma and Esophageal Cancer? A Systematic Review and Meta-Analysis.2020;9(2):507.

23. Valdivia A, Mingo G, Aldana V, Pinto MP, Ramirez M, Retamal C et al: Fact or fiction, it is time for a verdict on Vasculogenic Mimicry?2019;9:680.

24. Liu Y, Li F, Yang YT, Xu XD, Chen JS, Chen TL et al: IGFBP2 promotes vasculogenic mimicry formation via regulating CD144 and MMP2 expression in glioma. Oncogene.2018.

25. Sun B, Zhang D, Zhao N, Zhao X: Epithelial-to-endothelial transition and cancer stem cells: two cornerstones of vasculogenic mimicry in malignant tumors. Oncotarget.2017;8(18):30502-10.

26. Zhang S, Zhang D, Sun B: Vasculogenic mimicry: current status and future prospects. Cancer Lett.2007;254(2):157-64.

27. Kim HS, Won YJ, Shim JH, Kim HJ, Kim J, Hong HN et al: Morphological characteristics of vasculogenic mimicry and its correlation with EphA2 expression in gastric adenocarcinoma. Sci Rep.2019;9(1):3414.

28. Hujanen R, Almahmoudi R, Karinen S, Nwaru BI, Salo T, Salem A: Vasculogenic Mimicry: A Promising Prognosticator in Head and Neck Squamous Cell Carcinoma and Esophageal Cancer? A Systematic 
Review and Meta-Analysis. Cells.2020;9(2).

29. Cui J, Xi H, Cai A, Bian S, Wei B, Chen L: Decreased expression of Sox7 correlates with the upregulation of the Wnt/beta-catenin signaling pathway and the poor survival of gastric cancer patients. Int J Mol Med.2014;34(1):197-204.

30. Wang C, Guo Y, Wang J, Min Z: The suppressive role of SOX7 in hepatocarcinogenesis. PLoS One.2014;9(5):e97433.

31. Hu W, Han Y, Yang W, Xu B, Zhang W, Jin Z et al: Novel role of sex-determining region Y-box 7 (SOX7) in tumor biology and cardiovascular developmental biology. Semin Cancer Biol.2019.

32. Liu Q, Qiao L, Liang N, Xie J, Zhang J, Deng G et al: The relationship between vasculogenic mimicry and epithelial-mesenchymal transitions. J Cell Mol Med.2016;20(9):1761-9.

33. Sun D, Sun B, Liu T, Zhao X, Che N, Gu Q et al: Slug promoted vasculogenic mimicry in hepatocellular carcinoma. J Cell Mol Med.2013;17(8):1038-47.

34. Liu Z, Sun B, Qi L, Li H, Gao J, Leng X: Zinc finger E-box binding homeobox 1 promotes vasculogenic mimicry in colorectal cancer through induction of epithelial-to-mesenchymal transition. Cancer Sci.2012;103(4):813-20.

35. Fan YL, Zheng M, Tang YL, Liang XH: A new perspective of vasculogenic mimicry: EMT and cancer stem cells (Review). Oncol Lett.2013;6(5):1174-80.

36. Sun T, Zhao N, Zhao XL, Gu Q, Zhang SW, Che N et al: Expression and functional significance of Twist1 in hepatocellular carcinoma: its role in vasculogenic mimicry. Hepatology.2010;51(2):545-56.

37. Breier G, Grosser M, Rezaei M: Endothelial cadherins in cancer. Cell Tissue Res.2014;355(3):523-7.

38. Hendrix MJ, Seftor EA, Meltzer PS, Gardner LM, Hess AR, Kirschmann DA et al: Expression and functional significance of VE-cadherin in aggressive human melanoma cells: role in vasculogenic mimicry. Proc Natl Acad Sci U S A.2001;98(14):8018-23.

39. Cheng N, Brantley DM, Liu H, Lin Q, Enriquez M, Gale N et al: Blockade of EphA receptor tyrosine kinase activation inhibits vascular endothelial cell growth factor-induced angiogenesis. Mol Cancer Res.2002;1(1):2-11.

40. Mitra D, Bhattacharyya S, Alam N, Sen S, Mitra S, Mandal S et al: Phosphorylation of EphA2 receptor and vasculogenic mimicry is an indicator of poor prognosis in invasive carcinoma of the breast. Breast Cancer Res Treat.2020;179(2):359-70.

41. Ayala-Dominguez L, Olmedo-Nieva L, Munoz-Bello JO, Contreras-Paredes A, Manzo-Merino J, Martinez-Ramirez I et al: Mechanisms of Vasculogenic Mimicry in Ovarian Cancer. Front Oncol.2019;9:998.

\section{Tables}

Table 1. Clinicopathological features of 46 OSCC patients 


\begin{tabular}{|c|c|}
\hline Variable & No. of cases $(\%)$ \\
\hline \multicolumn{2}{|c|}{ Age (y); mean, 55} \\
\hline $20-29$ & $2(4)$ \\
\hline $30-39$ & $2(4)$ \\
\hline $40-49$ & $11(24)$ \\
\hline $50-59$ & $15(33)$ \\
\hline $60-69$ & $11(24)$ \\
\hline $70-79$ & $5(11)$ \\
\hline \multicolumn{2}{|l|}{ Sex } \\
\hline Male & $40(87)$ \\
\hline Female & $6(13)$ \\
\hline \multicolumn{2}{|c|}{ Differentiation status } \\
\hline Well & $34(74)$ \\
\hline Moderately & $12(26)$ \\
\hline \multicolumn{2}{|c|}{ T classification } \\
\hline $\mathrm{T} 1$ & $6(13)$ \\
\hline $\mathrm{T} 2$ & $24(52)$ \\
\hline T3 & $2(4)$ \\
\hline $\mathrm{T} 4$ & $14(30)$ \\
\hline \multicolumn{2}{|c|}{$\mathrm{N}$ classification } \\
\hline NO & $17(37)$ \\
\hline $\mathrm{N} 1$ & $12(26)$ \\
\hline N2 & $17(37)$ \\
\hline \multicolumn{2}{|c|}{ M classification } \\
\hline MO & $45(98)$ \\
\hline M1 & $1(2)$ \\
\hline Stage & \\
\hline
\end{tabular}

Page 12/19 


\begin{tabular}{|ll|}
\hline II & $4(9)$ \\
\hline III & $5(11)$ \\
\hline IV & $10(22)$ \\
\hline Recurrence & $27(59)$ \\
\hline No & \\
\hline Yes & $34(74)$ \\
\hline
\end{tabular}

Table 2. Associations between vasculogenic mimicry status and clinicopathological features in patients with OSCC 


\begin{tabular}{|c|c|c|c|c|}
\hline & \multirow{2}{*}{$\begin{array}{l}\text { No. of patients } \\
(n=46)\end{array}$} & \multicolumn{2}{|c|}{ Vasculogenic mimicry status } & \multirow[t]{2}{*}{$P$} \\
\hline & & $\begin{array}{l}\text { Negative } \\
(n=35)\end{array}$ & $\begin{array}{l}\text { Positive } \\
(n=11)\end{array}$ & \\
\hline \multicolumn{5}{|l|}{ Age $(y)$} \\
\hline$<55$ & 21 & 16 & 5 & 0.988 \\
\hline$\geq 55$ & 25 & 19 & 6 & \\
\hline \multicolumn{5}{|l|}{ Gender } \\
\hline Male & 40 & 30 & 10 & 1.000 \\
\hline Female & 6 & 5 & 1 & \\
\hline \multicolumn{5}{|c|}{ Differentiation status } \\
\hline Well & 34 & 27 & 7 & 0.441 \\
\hline Moderately & 12 & 8 & 4 & \\
\hline \multicolumn{5}{|l|}{ Tumor size } \\
\hline $\mathrm{T} 1+\mathrm{T} 2+\mathrm{T} 3$ & 32 & 22 & 10 & 0.133 \\
\hline $\mathrm{T} 4$ & 14 & 13 & 1 & \\
\hline \multicolumn{5}{|c|}{ Lymph node metastasis } \\
\hline Negative & 17 & 17 & 0 & $0.003^{*}$ \\
\hline Positive & 29 & 18 & 11 & \\
\hline \multicolumn{5}{|c|}{ Distant metastasis } \\
\hline Negative & 45 & 34 & 11 & 1.000 \\
\hline Positive & 1 & 1 & 0 & \\
\hline \multicolumn{5}{|l|}{ Stage } \\
\hline$I+I I+I I I$ & 19 & 17 & 2 & 0.092 \\
\hline IV & 27 & 18 & 9 & \\
\hline \multicolumn{5}{|l|}{ Recurrence } \\
\hline No & 34 & 25 & 9 & 0.701 \\
\hline Yes & 12 & 10 & 2 & \\
\hline
\end{tabular}


$\star P<0.05$ vs control group

Table 3. Correlation between vasculogenic mimicry and SOX7 expression in OSCC

\begin{tabular}{|lllll|}
\hline & No. of patients & \multicolumn{2}{l|}{ Vasculogenic mimicry status } & $P$ \\
\cline { 3 - 5 } & $(\mathrm{n}=46)$ & $\begin{array}{l}\text { Negative } \\
(\mathrm{n}=35)\end{array}$ & $\begin{array}{l}\text { Positive } \\
(\mathrm{n}=11)\end{array}$ & \\
\hline SoX7 & & & & \\
\hline Negative & 32 & 21 & 11 & $0.020^{\star}$ \\
\hline Positive & 14 & 14 & 0 & \\
\hline
\end{tabular}

$\star P<0.05$ vs control group

Figures 

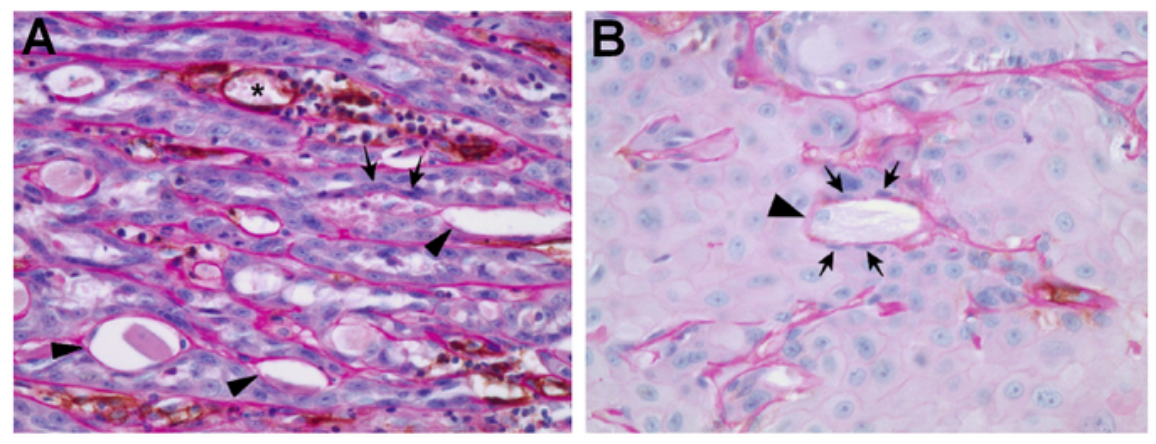

C

HN22
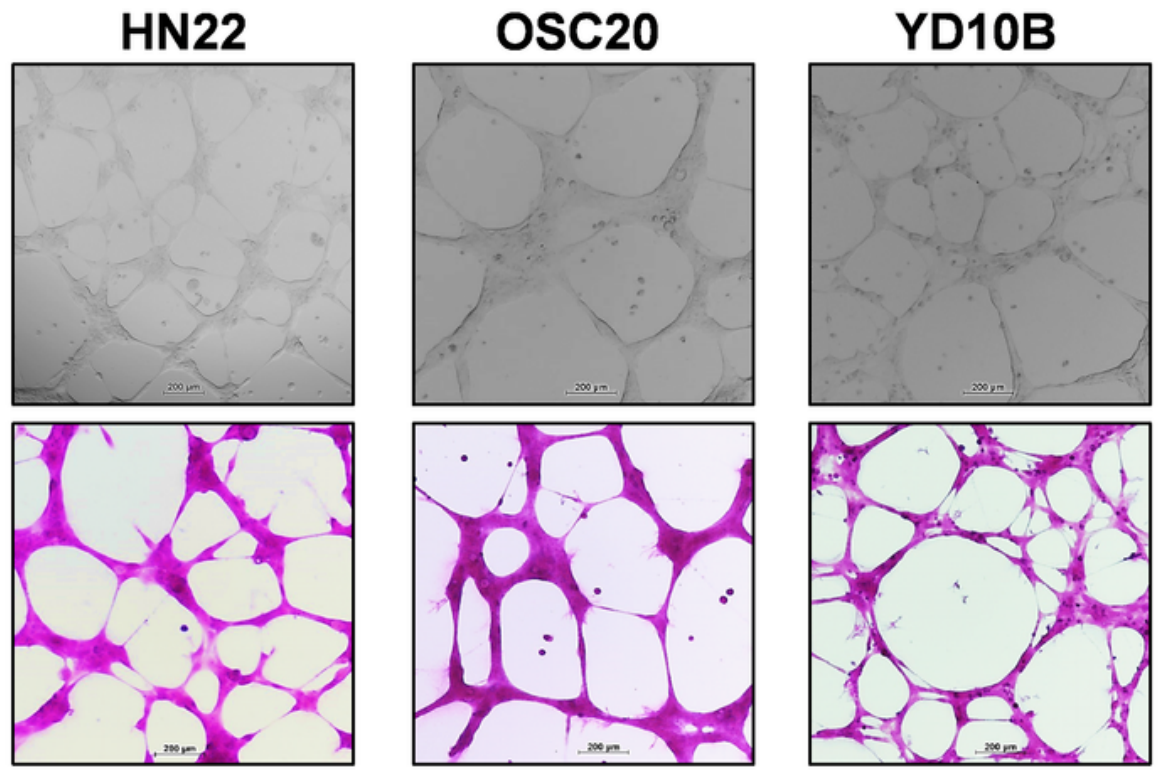

D

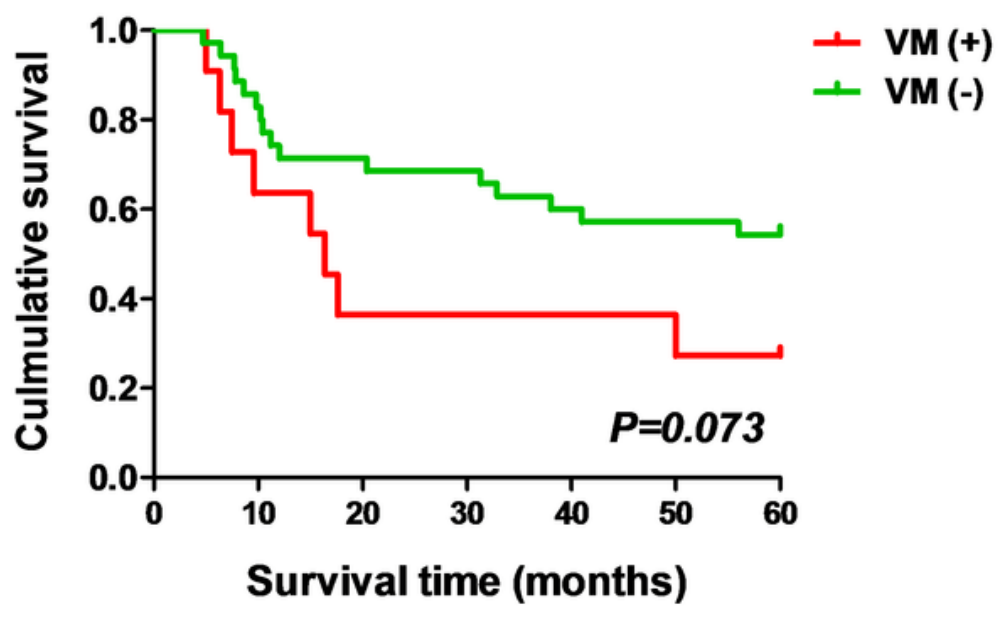

\section{Figure 1}

Vasculogenic mimicry (VM) in OSCC. (A and B) Representative images of CD31/PAS double staining in OSCC tissue sections. The arrowheads show CD31-/PAS+ tubular structures in a VM+ case. A vessel-like structure surrounded by tumor cells (arrows) contains red blood cells. Asterisk shows a blood vessel lined by CD31+ endothelial cells (original magnification, 400x). (C) Phase-contrast microscope images of channel formation were taken from various OSCC cell lines (top panel), and PAS-stained images of OSCC 
cell lines (bottom panel) (original magnification, 100x). (D) Kaplan-Meier survival curves of OSCC patients. VM+ patients showed a tendency toward poorer overall survival $(P=0.073)$.
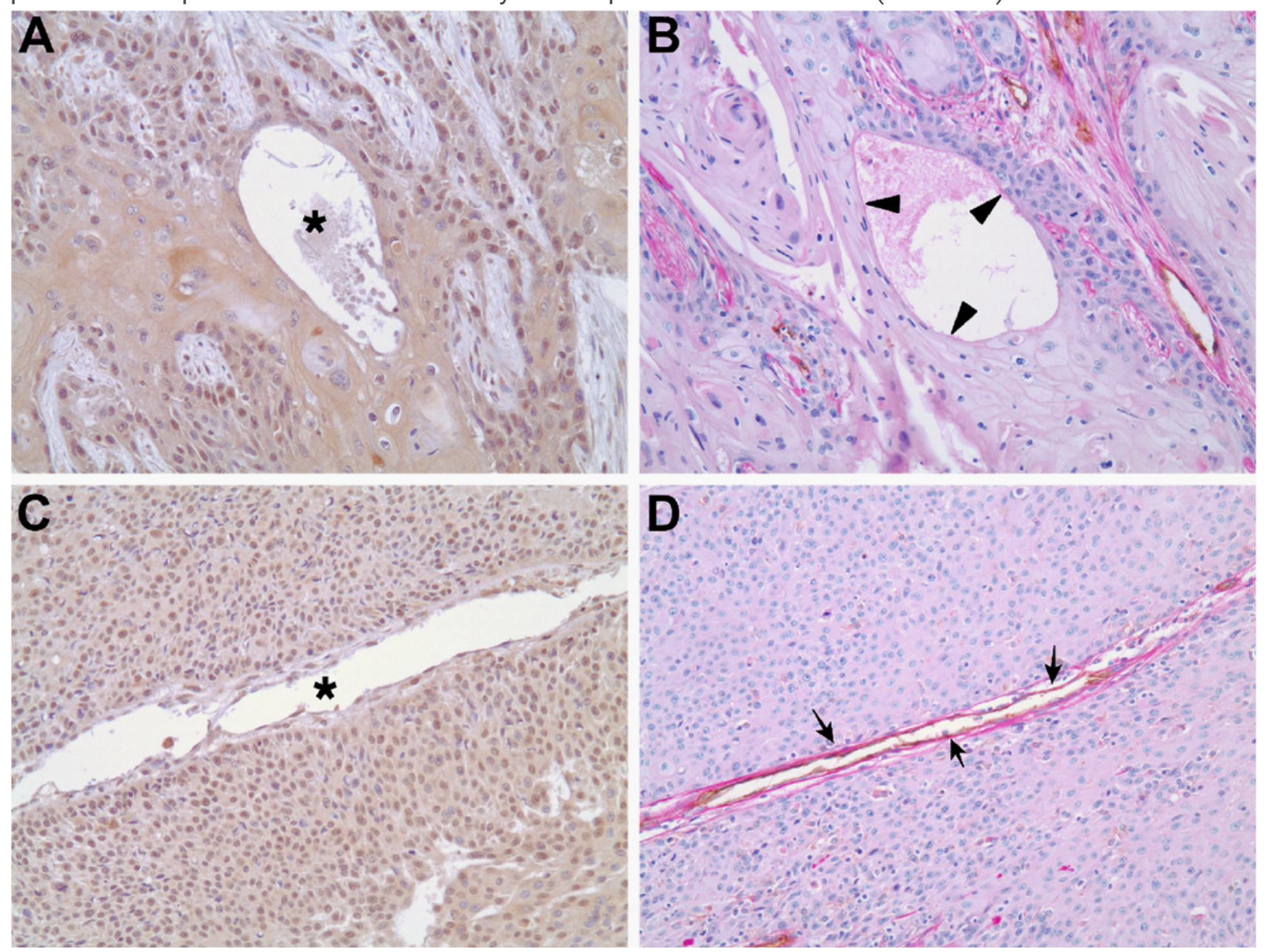

Figure 2

SOX7 immunohistochemical ( $A$ and $C$ ) and CD31/PAS double staining ( $B$ and $D$ ) in OSCC (original magnification, 200x). (A and B) A case showing diffuse nuclear staining of SOX7 has a lumen (asterisk) suggesting VM. However, the luminal side was negative for PAS staining (arrowheads). (C-D) Another SOX7+ case shows vasculature (asterisk) lined by CD31+ endothelial cells (arrows). 
A

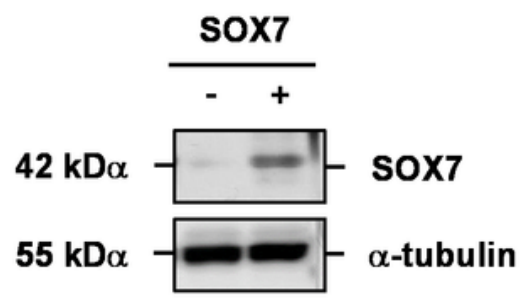

C

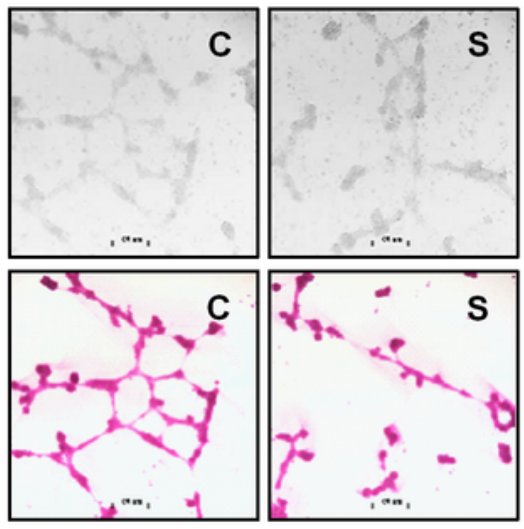

$\mathbf{E}$

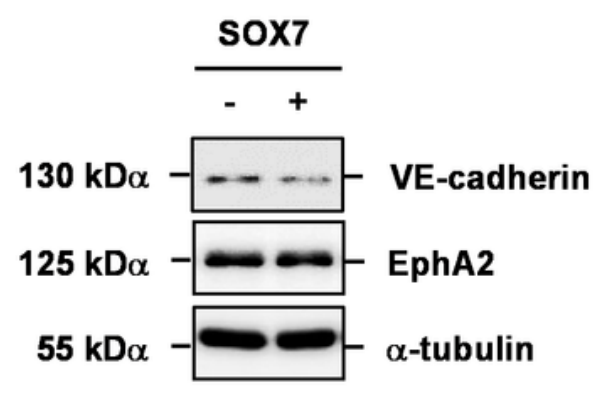

B

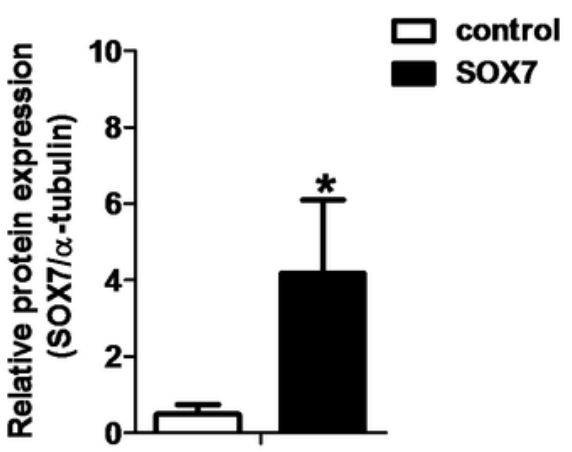

D

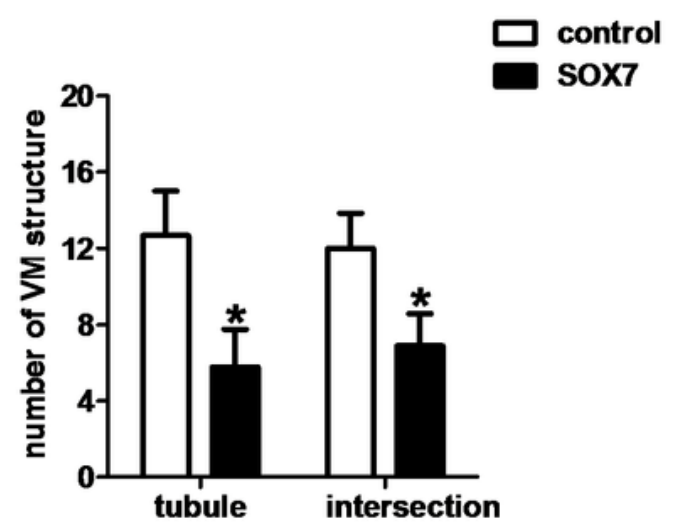

$\mathbf{F}$

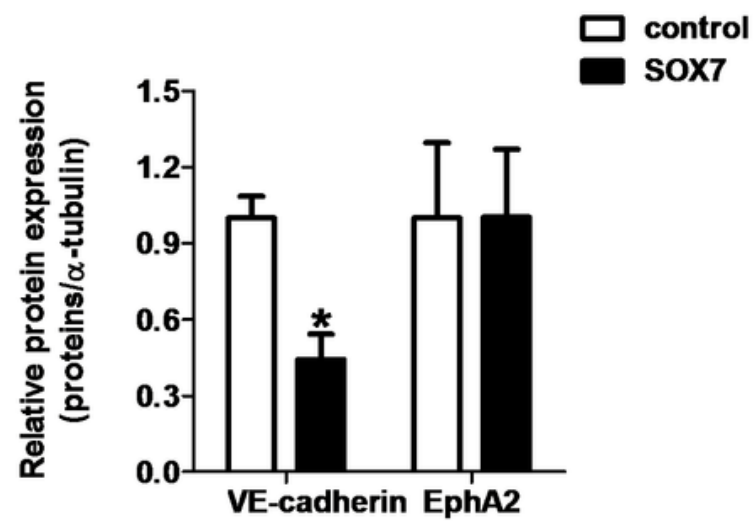

Figure 3

Inhibitory effect of SOX7 on VM channel formation in SCC-9 cells. (A and B) SOX7 expression in SCC-9 cells after transfection with pCMV6-SOX7 vector (SOX7 [S]) or pCMV6-empty (control [C]) as assessed by Western blot analysis. (C) phase-contrast microscopy images of channel formation in SCC-9 cells (upper row); PAS-stained images of SCC-9 cells grown on Matrigel for $24 \mathrm{~h}$ (lower row) (original magnification, 100x). (D) For quantitative analysis, five non-overlapping fields were selected from each culture well; 
graph shows the mean $\pm S D$ of three independent experiments. ${ }^{*} P<0.05$ vs control group. (E) Western blot analysis assessing the effect of exogenous SOX7 on the expression of VM-modulated proteins (VEcadherin and EphA2) in SCC-9 cells. (F) Graph shows the mean \pm SD of three independent experiments. $* \mathrm{P}<0.05$ vs control group.

A

B
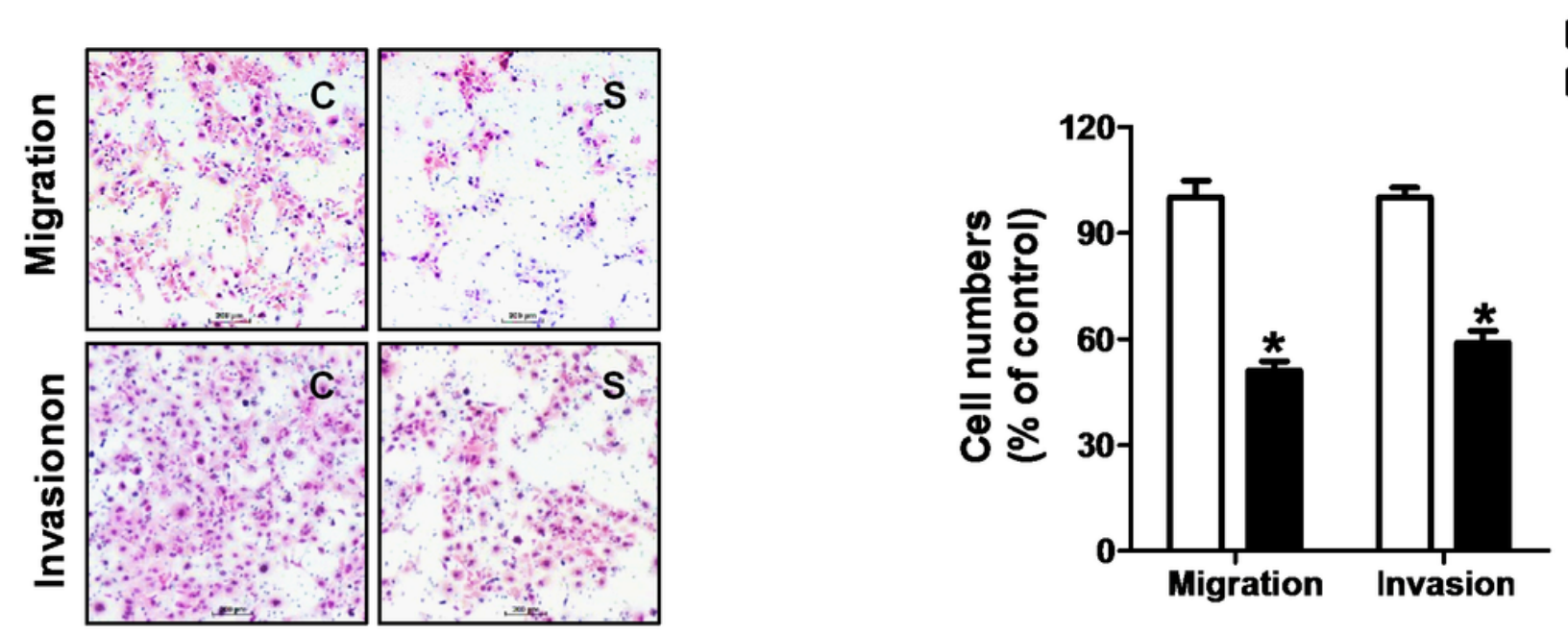

Figure 4

Migration and Matrigel invasion assay of SCC-9 cells (A) Cells overexpressing SOX7 exhibited impaired migration and invasion. (B) For quantitative analysis, five non-overlapping fields were selected from each culture well; graph shows the mean \pm SD of three independent experiments. ${ }^{P}<0.05$ vs control group.

\section{Supplementary Files}

This is a list of supplementary files associated with this preprint. Click to download.

- AdditionalFile1.docx 